\title{
THE PERCEIVED VIEWS OF PRINCIPALS AND SUPERVISORS TOWARDS THEIR ETHICAL LEADERSHIP IN SOME SELECTED PRIMARY SCHOOLS OF EASTERN ETHIOPIA
}

\author{
Birhanu Sintayehu Alemu $^{1 *}$; Bahar Adem Abdillahi \\ ${ }_{1,2}$ Department of Educational Planning and Management, \\ College of Education and Behavioral Sciences, Haramaya University \\ P.O. Box.138, Dire Dawa Ethiopia \\ 'biruhamah@gmail.com/birhanu.sintayehu@haramaya.edu.et; ${ }^{2 b a h a r a d e m @ y a h o o . c o m / b a h a r . a d e m @ h a r a m a y a . e d u . e t ~}$
}

Received: $27^{\text {th }}$ June 2020/ Revised: $05^{\text {th }}$ August 2020/ Accepted: 27 th August 2020

\begin{abstract}
How to Cite: Alemu, B. S., \& Abdillahi, B. A. (2020). The perceived views of principals and supervisors towards their ethical leadership in some selected primary schools of Eastern Ethiopia. Humaniora, 11(3), 183-192. https://doi.org/10.21512/humaniora.v11i3.6524
\end{abstract}

\begin{abstract}
The research's objectives were to assess the extent to which principals and supervisors practice ethical code of conduct in leading teachers in primary schools, identify differences among leaders related to their personal characteristics, and identify immoral practices leaders experience in the schools. The research participants were 120 principals, 63 supervisors, and 62 teachers selected using stratified and available sampling techniques. The quantitative data obtained through questionnaire were analyzed by descriptive and inferential statistics. The findings of the research reveal that school leaders are moderately ethical in their schools' administration. There is no significant difference in the dimensions of ethical leadership practice with reference to positions and fields of study school leaders possess. However, there is a significant difference in experience in a leadership position and academic qualification as well as between males and females. Teachers perceive that school leaders use mainly deception, abuse, harassment of subordinates, diminished dignity of employees, and breach of the agreement. It is suggested that school leaders should have professional scaffolding and training in fostering ethical leadership behavior to lead schools successfully. Those interested may conduct more detailed research considering secondary schools.
\end{abstract}

Keywords: principal views, supervisor views, ethical leadership, primary schools

\section{INTRODUCTION}

A leader has the potential to influence a subordinate intentionally or unintentionally. The responsibility of leadership necessitates an active quest for greater efficiency and effectiveness, which do not inadvertently lead people to more temptations than they can resist (Mihelič, Lipičnik, \& Tekavčič, 2010). Consequently, leaders' strong character must be evident through effective self-leadership and through their method of guiding others. Thus, leaders must rely on their internal voice and compass that points them in the ethical direction (Brown in Mihelič, Lipičnik, \& Tekavčič, 2010). Similarly, Downe, Cowell, and
Morgan (2016) have explained that the concept of leadership is broadly regarded as a significant role in promoting ethical behavior in organizations. The ways in which leaders' actions intersect with formal ethical guideline conformation, but the behavior has been little studied.

Presently, an increasing number of researchers are trying to research the ethical dimensions of leadership, including education (Langlois et al., 2014). Furthermore, in recent years, the ethics of practice has been a popular topic of discussion in many professional fields, including education (Kocabas \& Karakouml, 2009). Thus, an educational institution's success and the degree by which its aims 
may be reached depending on the educational leader and his/her art of effective management. Indeed, it has been the experience that administrators have the same probability of failing because they are seen as unfair and inefficient (Weinberg, 2014).

As for ethical leadership behavior, ethical leaders think about the disadvantages and consequences of their decisions in the organization. Mihelič, Lipičnik, and Tekavčič (2010) have mentioned behavior of ethical leaders, such as humble, take care of the common good, fight for justice, take responsibility, and show respect for each individual, set high ethical standards, and act accordingly. They always challenge themselves to influence the ethical values of the organization through their ethical behavior. They are perceived by their followers as honest, reliable, and courageous and show integrity. Thus, being ethical means acting fairly, thoughtful about others' wellbeing, and thinking about the consequences of one's actions. However, Mihelič, Lipičnik, and Tekavčič (2010) have mentioned that even if leaders grow up with a strong sense of good or evil, the bad behavior of others can also undermine their ethical sense. Therefore, most of the authors have agreed that ethical leaders tell about the identity, who they are, and what someone can become, how people live, and how to live better (Svara, 2014).

A leader's role is to guide the characters and behaviors of the followers towards the desired goal. Ethical leadership basically gives due emphasis on the leader's behavior and, therefore, separates individual characteristics, attitudes from real behavior (Mihelič, Lipičnik, \& Tekavčič, 2010). Likewise, Brown, Trevino, and Harrison (2005) have stated that ethical leadership has favorable consequences for followers and organization reflected in the perceived effectiveness of leaders, professional satisfaction of followers, greater dedication, and notification of problems. Similarly, leaders who do not provide ethical leadership and develop procedures that facilitate ethical conduct share responsibility with those who conceive, perform, and benefit from corporate crime (Perry, 2015).

Compared to the influences of ethical leaders, Brown, Treviño, and Harrison (2005) have pointed out that ethical leadership is the demonstration of normatively appropriate behaviors through personal actions and interpersonal relationships. The promotion of such behavior to followers is through bi-directional communication, strengthening, and decision making. To elaborate this more, Brown, Treviño, and Harrison (2005) have stated that ethical leaders act as appropriate behavior patterns and use reward and punishment to stimulate ethical behavior. Ethical leadership is about being an ethical role model, treating people fairly, and actively managing ethics in the organization (Hassan, Wright, \& Yukl, 2014; Hassan et al., 2013). Downe, Cowell, and Morgan (2016) have confirmed that ethical leadership is the ability to influence others ethically. It is an important determinant of effective leadership. Hence, ethical leadership is all about leader uses power and influence wisely and well.

As regards to the extent to which school leaders are ethical in their leadership, Arar et al. (2016) have emphasized on their research findings as characteristics of an ethics-oriented practice of school leadership, i.e., a way of leading where one's conduct, whether making a landmark decision, modeling the behavior or interacting with people, is firmly rooted in an ethical based, self-regulated professional judgment. Also, Kocabas and Karakouml (2009) have conducted research on ethics in school administration. The findings imply that a principal's ethical leadership is of great importance regarding educational organizations. Furthermore, the most important responsibility of school principals is to have an ethical perception of school administration.

In a national context, Amsale, Bekele, and Tafesse (2016) have highlighted as most of the teachers are considering that their leaders are not ethical in the sense that they do not treat them fairly and equitably. It is hardly considered the education institutions' diversity when they are not altruistic and not ethical models. Besides, Arar et al. (2016) have conducted research on ethical leadership in education and its relation to ethical decision-making. The findings reveal that to shape the ethical behavior of school leaders. It suggests paying attention to ethical aspects in the educational arena from all possible angles. Amsale, Bekele, and Tafesse (2016) have found out those leaders are perceived as moderately ethical. Surprisingly, their findings indicate that leaders who are not trusted by their teachers could only end up with poor performance, or failure if worst. Unless it leads institutions or schools to unnecessary dimensions like a small wound on one's body caused by cancer cells, if a person is not aware of the causes to be cancer and simply treats the wound alone, the whole body will gradually come to its end or dysfunctional (Amsale, Bekele, \& Tafesse, 2016).

With pertaining to immoral practice of school leaders experienced over subordinates, Mihelič, Lipičnik, and Tekavčič (2010) have discovered that ethical behavior should be ethically recognized by way of good and right as opposed to bad or wrong in a given situation. Likewise, ethics violations by school leaders and members have negative repercussions for the entire institution. Similarly, the same research findings have revealed that ethics is the code of values and moral principles that guide individual or group behavior with respect to what is right or wrong. Ethical behavior of school leader is ought to acceptable legally and morally to the larger communities (Mihelič, Lipičnik, \& Tekavčič, 2010). Hence, the behavior which showed and applied by school leaders over subordinates is unaccepted by the broad community. It is obvious that he/she exercised immoral practices. However, past research related to the principals indicates that most of them are no better than 'fair' (MoE, 2015). The foundation for a theory of practice in school leadership is grounded by three principles; a systematic understanding of adults' 
behavior at work in the school, an understanding of the organizational context in which people work, and leader behavior (MoE, 2015).

Therefore, the present research is worth studying due to the following justifications; first, almost no research studies have been directed to examine the ethical leadership practices of school leaders in primary schools. Second, if the over mentioned problems remain unsolved, schools cannot meet its mission and could not equip and build exemplar ethical citizens for the future. To strengthen this, Kocabas and Karakouml (2009) have conducted research on ethics in school administration. It reveals that school leaders have a key role in managing schools because they are the main decision-makers, school leaders, and have more responsibilities than the other staff. In such an ethical school environment, success is a definite outcome of the educational process, and conducting this research on the area is paramount important. The second, Ethiopian government gives due emphasis to primary school improvement and leadership reforms. The rationale behind giving due prominence to primary school leadership is the educational quality, access, and enrolment patterns in upper primary, secondary, TVET, and higher education. It depends largely on the evolution of enrollment in the improvement and application of the early grade of ethical leadership in schools (MoE, 2015). This implies that primary education remains the highest priority for the Government of the Federal Democratic Republic of Ethiopia (GFDRE) and receives the highest share from the education sector's total estimated expenditure (MoE, 2015). Therefore, this research aims to examine principals' and supervisors' views towards their practices of ethical leadership in primary schools of Eastern Ethiopia.

Regarding the theoretical framework, even though the theoretical formu $\neg$ lations about the ethical leadership process remain tentative, Northouse (2013) has developed its ground. Ethical theories can be thought of as falling within two broad domains; theories about leaders' conduct-actions of leaders and theories about leaders' character-who they are as people. Theories emphasize the consequences of leader behavior (teleological approach) or the rules that govern their behavior (deontological approach). Virtue-based theories focus on the character of leaders, as indicated in Table 1.

Table 1 Domains of Ethical Leadership

\begin{tabular}{l}
\hline \multicolumn{1}{c}{ Conduct } \\
\hline Consequences (teleological
\end{tabular}

Domains of Ethical Leadership (Northouse, 2013)
Teleological theories have derived from the Greek word telos. It means 'ends' or 'purposes', tries to answer questions about right and wrong by focusing on whether a person's conduct will produce desirable consequences. From the teleological perspective, the question 'what is right?' is answered by looking at results or outcomes. In effect, the consequences of an individual's actions determine the goodness or badness of a particular behavior. Deontological theory is as well derived from the Greek word deos, which means duty. Whether a given action is ethical rests not only with its consequences (teleological) but also with whether the action itself is good. Telling the truth, keeping promises, being fair, and respecting others are all examples of inherently good actions, independent of the consequences. The deontological perspective focuses on the actions of the leader and his/her moral obligations and responsibilities to do the right thing. The second set of theories approaches ethics from the viewpoint of a leader's character or virtue-based theories; they focus on who leaders are as people. A moral person demonstrates the virtues of courage, temperance, generosity, self-control, honesty, sociability, modesty, fairness, and justice. In essence, virtue-based ethics is about being and becoming a good and worthy human being.

Beyond this, Kalshoven, Den Hartog, and De Hoogh (2011) have distinguished seven ethical leader behaviors. They are fairness, people-orientation, role clarification, ethical guidance, environment orientation, power-sharing, and integrity. Besides, Yukl et al. (2013) have designed five criteria to measure the behavior of ethical leaders such as honesty, fairness, integrity, sets an example, and concern for value. Finally, Amsale, Bekele, and Tafesse (2016) have identified that the major characteristics of ethical leaders are integrity, trustworthiness, honesty, and transparency. Therefore, the researchers set a framework and have taken common standards to measure the behavior of ethical leaders such as honesty, fairness, and a peopleoriented approach as a benchmark.

Therefore, the research tries to answer these research questions; first, to what extent do principals and supervisors follow ethical codes of conduct in their leadership in the primary schools of Eastern Ethiopia? Second, is there any difference in ethical leadership among school leaders in reference to their position, sex, the field of specialization, service years in a leadership position, and academic qualification? Third, what immoral practices do school leaders experience across the school communities?

\section{METHODS}

The research is employed as a descriptive survey research design. The basic rationale behind applying this design is to collect data to answer questions about people's opinions, beliefs, attitudes, behaviors, and demographic composition on a certain area of the topic of interest (Mills \& Gay, 2016). This descriptive 
survey research design is particularly useful in studying at describing behaviors and gathering people's perceptions, opinions, attitudes, and beliefs about a current issue in education (Vanderstoep \& Johnson, 2008). Besides, this design is appropriate to collect and analyze data at a time to conclude in such limited time and budget. Moreover, based on Creswell's (2012) suggestions, it also uses a quantitative approach for a research strategy that requires collecting numerical data, quantifying collected data, and analyzing data from selected school principals, supervisors, and teachers.

Therefore, the first categories of populations of the research are 361 primary school principals and supervisors with the 2018/19 Haramaya University who attended the Postgraduate Diploma in School Leadership program (PGSL) training. The training program is designed by the ministry of education to support and empowers principals and supervisors in improving their practice and bringing about real change in their schools. This program is offered through a face-to-face modality in two summers and a one-semester workplace-based reflective action phase (two round tutorials) between the two summers. The researchers use stratified proportional sampling techniques to select participants from 236 principals and 125 supervisors with a total of 361 . In addition, 62 teachers are participated from 52 primary schools via the available sampling technique to triangulate data collected from school leaders. The primary data are collected through questionnaires from principals, supervisors, and teachers who have been working in selected primary of Eastern Ethiopia in the academic year of 2018/19.

To determine sample size from both school principals and supervisors, the researchers apply Yamane (1967) formula $\mathrm{n}=\mathrm{N} /\left(1+\mathrm{N}^{*} \mathrm{e}^{2}\right)$, which $\mathrm{N}=$ total population, $\mathrm{n}=$ sample size, $\mathrm{e}=$ error rate/ margin of error $(0,05)$. It provides a simplified formula to calculate sample sizes an d guess: $95 \%$ confidence level $\mathrm{P}=0,05$. Thus, sample size determination is calculated as follows:

$$
\begin{aligned}
\mathrm{N} & =\mathrm{N} /\left(1+\mathrm{N}^{*} \mathrm{e}^{2}\right) & & =361 /\left(1+361 * 0,05^{2}\right) \\
& =361 / 1,9025 & & =190
\end{aligned}
$$

Table 2 Population and Sample Size

\begin{tabular}{lccc}
\hline Categories & $\boldsymbol{N}$ & $\boldsymbol{n}$ & Sampling technique \\
\hline Teachers & 1300 & 62 & available \\
Principal & 236 & 124 & stratified \\
Supervisors & 125 & 66 & stratified \\
\hline Total & 1661 & 252 & \\
\hline
\end{tabular}

Table 2 depicts the sample size of the research as 124 principals, 66 supervisors, and 62 teachers with a total of 252 who are selected using stratified and available sampling techniques.

The researchers have developed questionnaires on their own to secure data. To increase the questionnaire's validity, reliability, and practicability, a pilot test has several purposes (Cohen, Manion, \& Morrison, 2007). To check the validity of the instrument, area expertise from Haramaya University is consulted, and their comments are incorporated, and finally, the instruments are converted to local languages (Afaan Oromo and Amharic) to reduce possible language barriers. Moreover, upon the experts' advice, necessary adjustments are made; for example, two items are omitted from 35 items of the questionnaire, which is reduced to 33 . In addition, to triangulate secured data from the school leaders, ten items designed to examine immoral practices that school leaders experienced over subordinates are checked its practicability. Additionally, for the reliability of the items, a pilot test uses Cronbach alpharonbach's alpha, which is the most common way to assess selfreport items (Vanderstoep \& Johnson, 2008). The participants are 30 principals, ten supervisors, and 15 teachers from 10 randomly selected primary schools in Haramaya woreda and surrounding.

As depicted in the Table 3, for all sub-scale items, approximately $(\alpha>0,70)$ which is an average $0,786>0,70$. As a rule of thumb, for internal or interitem reliability if $\alpha=0,70$ or more usually is treated as an acceptable level of reliability in most social sciences research (Mark, 2001). The pilot test result indicates 0,786 on average, which is acceptable as the Vanderstoep and Johnson's (2008) work.

Table 3 Reliability Test Summary

\begin{tabular}{lcccccc}
\hline \multirow{2}{*}{ Themes of the sub-scale Items } & \multicolumn{3}{c}{ Pilot result } & \multicolumn{3}{c}{ Study result } \\
\cline { 2 - 7 } & \# of items & N & A & \# of items & N & $\boldsymbol{\alpha}$ \\
\hline Honesty as code of conduct & 7 & 40 & 0,821 & 7 & 183 & 0,840 \\
Fairness as ethical code of conduct & 7 & 40 & 0,738 & 7 & 183 & 0,743 \\
Integrity as ethical code of conduct & 11 & 40 & 0,831 & 10 & 183 & 0,833 \\
People orientation as ethical code of conduct & 10 & 40 & 0,754 & 9 & 183 & 0,758 \\
Overall ethical code of conducts & 35 & 40 & 0,786 & 33 & 183 & 0,793 \\
Immoral practice of school leaders & 10 & 15 & 0,877 & 10 & 62 & 0,832 \\
\hline
\end{tabular}


The obtained data are first coded and edited. Amended and corrected data are analyzed via applied descriptive and inferential statistics. To interpret data comprehensively, the investigators use descriptive statistics (percentage, frequencies, mean, and standard deviation) to describe the nature of the data and the respondents' features. Moreover, inferential statistics (independent t-test and one way ANOVA) are employed to compare significant mean differences in ethical leadership among school leaders regarding their position, sex, the field of specialization, service years in a leadership position, and academic qualification.

\section{RESULTS AND DISCUSSIONS}

Table 4 displays that the majority of the school leaders expressed a moderate level of ethical behavior. It also indicates four domains of ethical behavior with expected and obtained mean score (M) and standard deviation (SD).

Table 4 indicates a summary of 33 items in which participants are asked about the dimensions of school leaders' ethical behavior. Then the results are summarized and presented. As can be evidenced in Table 4, participants of the research have a positive attitude about the ethical behavior of school leaders with an expected mean of 82,5 and obtained a mean of 122,5 and $\mathrm{SD}=24,15$.

As regards to independent domain of ethical behavior of school leaders, Table 4 depicts that the expected and obtained mean score of honesty character of school leaders is 17,5 and $26,88(\mathrm{SD}=$ $4,95)$, fairness 17,5 and $25,55(\mathrm{SD}=4,72)$, integrity 22,5 and $34,5(\mathrm{SD}=6,22)$, and people-orientation 25 and 35,6 $(\mathrm{SD}=8,26)$ respectively. Amsale, Bekele, and Tafesse's (2016) results show that everyone wants to be fully confident in their leaders in every setting.
To be fully confident, they have to believe that their leaders are individuals of strong character and solid integrity. These results indicate that school leaders are usually honest, fair, integrity, and people-oriented to their subordinates. However, the experience is still needed to reach the expected level and standard for consistently high-level leaders in ethics.

By comparison, the largest mean score goes to the honesty character $(26,88)$. In contrast, the lowermost mean results go to the people-orientation $(35,6)$, even though there is a disparity in mean and standard deviation for each dimension of the ethical behavior of school leaders. The four disaggregated standards of ethical leadership found are above average and in a similar range of high level.

Therefore, the findings reveal that the degree to which school leaders are ethical in their leadership is moderate. This result is replicated with previous studies conducted by Amsale, Bekele, and Tafesse (2016), who indicate that the study found out those leaders in the sample universities are perceived as moderately ethical. Moreover, the research findings conducted in Florida (Florida Department of Education, 2008) reveals that the three-guiding code of ethics for educational leaders. First, the educator values the value and dignity of each person. Second, the educator's main professional concern will always be for subordinates and the development of the student's potential. Third, they must be aware of the importance of maintaining the respect and trust of colleagues, students, parents, and other community members. The educator is committed to achieving and maintaining the highest degree of ethical conduct. To examine whether there is a significant difference in the ethical leadership of school leaders and their position (supervisors and principals), the researchers are employed an independent t-test to compute the mean among the groups that can be seen in Table 5.

Table 4 Expected and Obtained Mean on Dimensions of Ethical Behavior of School Leaders

\begin{tabular}{lcccc}
\hline \multicolumn{1}{c}{ Ethical domains } & Number of items & Expected mean & Obtained mean & SD \\
\hline Perceived Honesty & 7 & 17,5 & 26,88 & 4,95 \\
Perceived Fairness & 7 & 17,5 & 25,55 & 4,72 \\
Perceived Integrity & 9 & 22,5 & 34,47 & 6,22 \\
Perceived People Orientation & 10 & 25 & 35,6 & 8,26 \\
Perceived Overall Ethical Domains & 33 & 82,5 & 122,5 & 24,15 \\
\hline
\end{tabular}

Table 5 Group Statistics by Position and Independent t-test

\begin{tabular}{lccccccccc}
\hline & & & \multicolumn{7}{c}{ t-test for Equality of Mean } \\
\cline { 7 - 10 } \multicolumn{1}{c}{ Positions } & N & Mean & SD & F & Sig. & T & Df & Sig. (2-tailed) & MD \\
\hline Supervisors & 63 & 3,74 & 0,57 & 1,52 & 0,444 & 0,247 & 181 & 0,805 & 0,092 \\
Principals & 120 & 3,71 & 0,61 & & & 0,253 & 134,13 & 0,801 & 0,092 \\
\hline
\end{tabular}

* The mean difference is significant at the 0,05 level (2-tailed) 
There is no significant difference in mean scores for supervisors $(M=3,74 ; S D=0,57)$ and principals $(M=3,71 ; S D=0,61 ; t(181)=0,247 ; p=0,805$, twotailed). The magnitude of the differences in the means (mean difference $=0,92,95 \% C I$ : -645 to 0,829 ) is very small (eta squared $=0,003$ ). Therefore, the statistical results suggest that school leaders' position has no effect on the ethical leadership practices of the school leaders.

Independent t-test is used to compute the dimensions of ethical leadership scores for male and female. The tests results are briefed and presented in the Table 6.

There is significant difference in scores for male $(M=3,68 ; S D=0,61)$ and female $(M=3,9 ; S D$ $=0,45 ; t(181)=-2,39 ; p=0,018<0,05$, two-tailed). The magnitude of the differences in the means (mean difference $=-1,21,95 \% C I$ : $-2,222$ to $-0,215$ ) is very small (eta squared $=0,030$ ).

Thus, the research's findings indicate that there is a statistically significant difference between male and female school leaders. Therefore, gender likely has an effect on exercising ethical leadership among male and school leaders, where female school leaders are more ethical than male school leaders. However, this finding diverges with Arar et al. (2016). They have reported on their findings as there is no significant difference between men and women on ethical leadership.

An Independent t-test is employed to compare the dimensions of ethical leadership scores for two groups of school leaders specialized by school leadership and non-school leadership). The test results are briefed and presented in Table 7.

There is no significant difference in mean scores for school leaders who specialized in school leadership $(M=3,68 ; S D=0,70)$, and those who are appointed by experience, gift, and talent (not specialized in educational leadership $(M=3,73 ; S D=0,58 ; t(181)$ $=-0,48 ; p=0,631$, two-tailed). The magnitude of the differences in the means (mean difference $=-0,222$, $95 \% C I:-1,132$ to 0,688 ) is very small (eta squared $=0,001)$. Therefore, the results have suggested that the field of specialization has no effect on the code of conduct for ethical leadership of school leaders.

One-way ANOVA tests are used to see the difference among five groups in service years in a leadership position with scores of ethical leadership dimension. The results are presented in Table 8.

Participants are categorized into three groups according to their service years in a leadership position (G1: 5years or fewer; G2: 6 to 10 years; G3: 11 years and above). There is a statistically significant difference at the $p<0,05$ level in dimensions of ethical leadership scores for the three service year groups in leadership position: $\mathrm{F}(4,178)=3,52 ; p=0,009$. Despite reaching statistical significance, the actual difference in mean scores between the groups is medium $(3,75,3,57$, and $3,93)$. The effect size calculated uses eta squared, eta squared $=$ Sum of squares between groups divided by the total sum of squares is 0,08 , which is Cohen's

Table 6 Group Statistics by Gender and Independent t-test

\begin{tabular}{lccccccccc}
\hline & & & \multicolumn{7}{c}{ t-test for Equality of Mean } \\
\cline { 7 - 11 } \multicolumn{1}{r}{ Gender } & $\mathbf{N}$ & Mean & SD & F & Sig. & T & Df & Sig. (2-tailed) & MD \\
\hline Male & 158 & 3,68 & 0,61 & 3,85 & 0,051 & $-2,39$ & 181 & 0,018 & $-1,21$ \\
Female & 25 & 3,9 & 0,45 & & & $-2,98$ & 39,55 & 0,005 & $-1,21$ \\
\hline
\end{tabular}

Table 7 Group Statistics by Field of Specialization and Independent t-test

\begin{tabular}{lccccccccc}
\hline & & & & \multicolumn{7}{c}{ t-test for Equality of Mean } \\
\cline { 7 - 11 } Educational background & $\mathbf{N}$ & Mean & SD & F & Sig. & T & Df & Sig. (2-tailed) & MD \\
\hline Educational leadership & 33 & 3,68 & 0,70 & 1,95 & 0,16 & $-0,48$ & 181 & 0,63 & $-0,22$ \\
Non-Leadership & 150 & 3,73 & 0,58 & & & $-0,42$ & 42,12 & 0,67 & $-0,22$ \\
\hline
\end{tabular}

Table 8 Group Statistics by Service Years in Leadership Position and One-Way ANOVA

\begin{tabular}{lccccccccc}
\hline Descriptive & \multicolumn{1}{c}{ ANOVA Summary } \\
Service year & N & Mean & SD & SV & SS & df & MS & F & Sig. \\
\hline$<$ Years & 82 & 3,75 & 0,57 & Between Groups & 50,61 & 2 & 25,30 & 4,59 & 0,011 \\
6-10 Years & 67 & 3,57 & 0,63 & Within Groups & 992,19 & 180 & 5,51 & & \\
$>11$ Years & 34 & 3,93 & 0,50 & Total & 1042,80 & 182 & & & \\
\hline Total & 183 & 3,75 & 0,57 & \multicolumn{1}{c}{} & & \\
\hline
\end{tabular}


(1988) terms would be considered a medium effect size. Cohen classifies 0,01 as a small effect, 0,06 as a medium effect, and 0,14 as a large effect. To know exactly where the differences among the groups occur, Post-hoc comparisons using the Tukey HSD test indicates that the mean score for Group $2(M=3,57$; $S D=0,63)$ is significantly different from Group $3(M$ $=3,93 ; S D=0,50)$. Group $1(M=3,75 ; S D=0,57)$ does not differ significantly from either Group 1 or 3 .

One-way ANOVA tests are used to compare the mean scores of three groups categorized based on academic qualification with dimensions of ethical leadership. The results are presented in Table 9.

One-way ANOVA tests are employed to compare the mean scores of three groups categorized based on academic qualification with dimensions of ethical leadership. Participants are divided into three groups according to their level of academic qualifications (G1: Certificate, G2: Diploma, G3: Degree). There is a statistically significant difference at the $p<0,05$ level in dimensions of ethical leadership scores for the three-level of academic qualification groups: F (2, $180)=6,69 ; p=0,002$. Despite reaching statistical significance, the actual difference in mean scores between the groups is medium $(4,25,3,87$, and 3,59$)$. The effect size of eta squared is 0,07 , which is Cohen's (1988) terms would be considered a medium effect size. To know exactly where the variances among the groups occur, Post-hoc comparisons using the Tukey HSD test indicate that the mean score for Group 2 $(M=3,87 ; S D=0,58)$ is significantly different from Group $3(M=3,59 ; S D=0,58)$. Group $1(M=4,25 ; S D$ $=0,49$ ) does not differ significantly from either Group 2 or 3 .

Figure 1 gives information about what immoral practice school leaders experienced over subordinates while leading their respective schools.

Table 9 Group statistics by Academic Qualification and One-way ANOVA

\begin{tabular}{lccccccccc}
\hline Descriptive & \multicolumn{1}{c}{ ANOVA Summary } \\
Items & N & Mean & SD & SV & SS & df & MS & F & Sig. \\
\hline Diploma & 3 & 4,25 & 0,49 & Between Groups & 72,18 & 2 & 36,09 & 6,69 & 0,00 \\
Degree & 78 & 3,87 & 0,58 & Within Groups & 970,6 & 180 & 5,392 & & \\
Master & 102 & 3,59 & 0,58 & Total & 1042,80 & 182 & & & \\
\hline Total & 183 & 14,88 & 0,60 & \multicolumn{1}{c}{} & \\
\hline
\end{tabular}

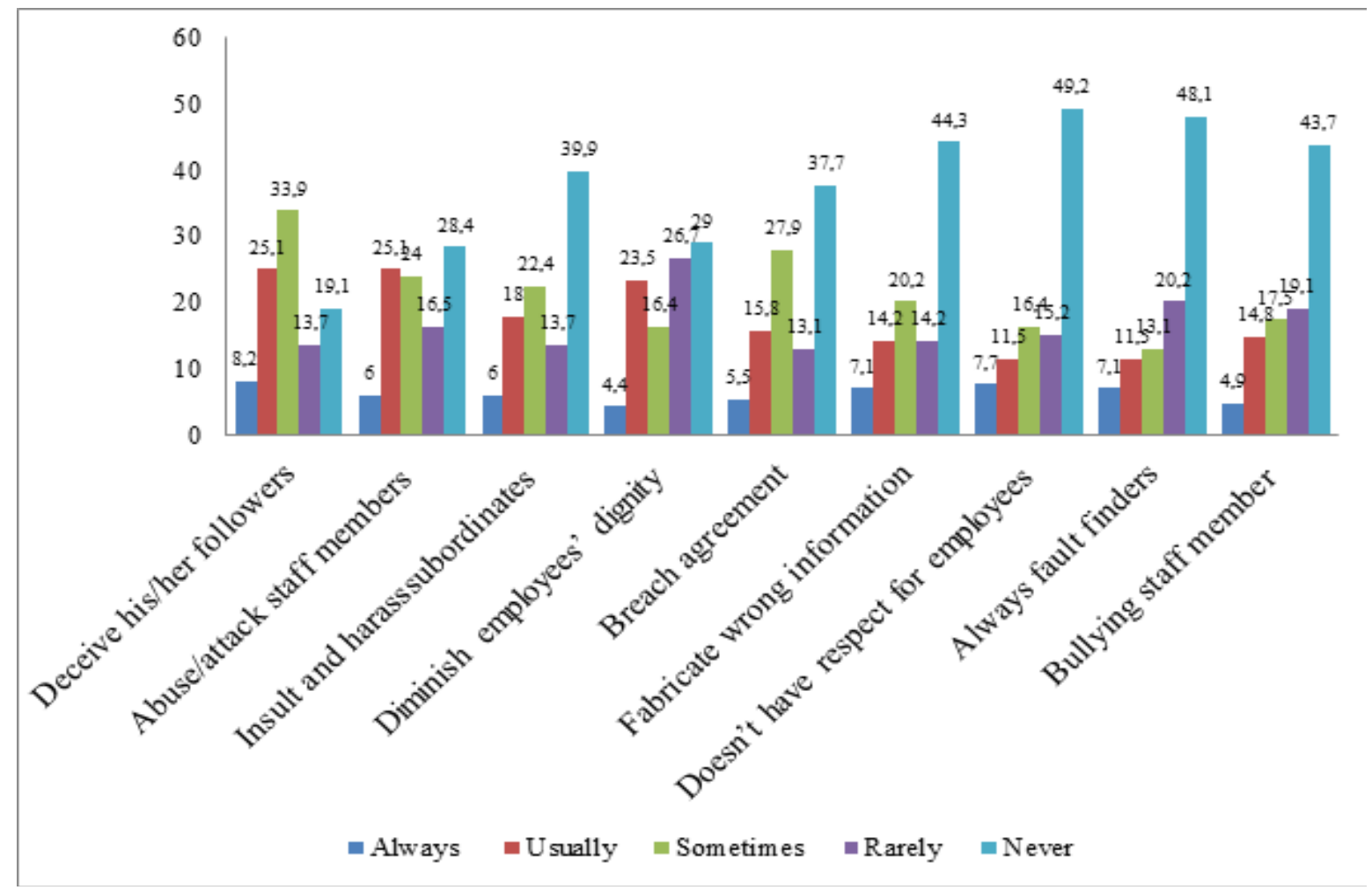

Figure 1 Immoral Practices School Leaders Experienced over Subordinates 
As shown in Figure 1, much can be determined regarding what immoral practice school leaders most often practiced over their subordinates as perceived by teachers. It shows that most teachers $(33,9 \%)$ note that their school leaders sometimes deceive his/her subordinates. While $25,1 \%$ and $19,1 \%$ respond, the frequency rating is usually and never, respectively.

Also, results indicate that school leaders are liable to abuse/attack staff members as the most respondents have replied that $28,4 \%$ never, $25,1 \%$ usually, and $24 \%$ sometimes. Furthermore, participants respond that school leaders insult and harass their subordinates in this regard $39,9 \%$ of them have said never, $22,4 \%$ sometimes, and other $18 \%$ have said usually. Respondent teachers indicate that school leaders diminish employees' dignity with likelihood. In these aspects $29 \%, 26,7 \%$, and $23,5 \%$ them imply as the frequencies are never, rarely, and usually in respective. Similarly, in responses on school leaders breaching $37,7 \%$ of them indicate never, but $27,9 \%$, and $15,8 \%$ of them mention as this happens sometimes and usually respectively. A majority $(44,3 \%)$ of respondents have replied saying that school leaders never fabricate wrong information, however $20,2 \%$ of them have said sometimes and 14,2\% believe as it is usual event. Participants are also asked whether school leaders do not have respect to their workers. The $49,2 \%$ of them respond by indicating the frequency of the practice at never, $16,4 \%$ of them sometimes, and the remaining $(15,2 \%)$ of them have said rarely. Furthermore, when respondents are asked whether school leaders always fault finders, $48,1 \%$ of them rated at never, the rating of $20,2 \%$ and $13,1 \%$ of them are rarely and sometimes respectively. Finally, most $(43,7 \%)$ of respondent teachers state that the likelihood of school leaders bullying staff members is never happened. Those who reacted rarely and sometimes are $19,1 \%$ and $17,5 \%$ respectively.

These findings show across several distinctive questions that school leaders have a moderate likelihood of immoral practicing over their subordinates. This result is consistent with previous studies conducted by Mihelič, Lipičnik, and Tekavčič (2010). The research on ethical leadership reveals that leadership in an organization holds the responsibility of developing and sustaining conditions in which people are likely to behave themselves and minimize conditions in which they may be tempted to misbehave. On the other hand, Bowen, Bessette, and Cham (2006) have conducted research on including ethics in the study of educational leadership. It shows that educational leadership faculty must serve as role models for those entering the field. Schools are conceived to be ethical organizations.

As shown in Figure 1, school leaders are somewhat likely to express immoral practices over their subordinates, such as deceive his/her subordinates, abuse/attack staff members, insulting and harass subordinates, diminishing employees' dignity, and breaching the agreement. It is also through the work of Mihelič, Lipičnik, and Tekavčič (2010) that indicate school has to be personal, human, and individual when unethical behavior is uncovered, it is important to act swiftly and decisively. Similarly, Kocabas and Karakouml (2009) conduct a study on ethics in school administration. It states that having moral responsibility and ethical standards are essential elements; however, they have no meaning without practice. Hence, these findings represent a conclusively significant necessity for school leaders to follow acceptable ethical behavior and always prioritize thinking ethically.

\section{CONCLUSIONS}

The research aims to examine the views of principals and supervisors towards their practices of ethical leadership in primary schools of Eastern Ethiopia. Three basic leading questions are formulated to guide the research. Based on the results of the research, the conclusions and recommendations are made.

First, it is possible to conclude that school leaders are moderately ethical in their direction. Thus, it is recommended that Eastern Ethiopia primary schools' education bureau officials should exercise a purposeful emphasis over ethical leadership, working to equip and build school leaders by enhancing their skills via training and development. To support this, Kocabas and Karakouml (2009) have indicated the need for qualified school leaders who have special training related to ethical leadership to maintain ethical school governance. Schools and universities should provide this necessary training and support for administrators cooperatively. This may shape the ethical behavior of school leaders. To strengthen this, Mihelič, Lipičnik, and Tekavčič (2010) have reported that leaders are the primary influence on ethical conduct in an organization and are responsible for the norms and codes of conduct that guide employees. Secondly, school leaders may influence school culture and the environment, as stated by Kocabas and Karakouml (2009). It shows that educational administrators are supposed to manage not simply an organization but establishing an ethical environment.

Secondly, there is no statistical mean significant difference on a position of school leaders between supervisors and principals; and on the field of specialization between (school leaders who specialized by school leadership and school leaders who are appointed by experience, gift, and talent (not specialized by educational leadership). However, there is a statistically significant difference found between genders (males and females). Thus, gender has an effect on exercising ethical leadership among male and female school leaders. These results show that it is possible to conclude that female school leaders are more ethical than male school leaders in leading schools. A one-way ANOVA test further depicted no statistically significant variance in service year in a leadership position and academic 
qualification. Therefore, it is suggested that school administrators should appoint more female school leaders on the school leadership post. Alternatively, it is recommended that school leaders should provide capacity building training for male school leaders to foster their ethical leadership skills. Likewise, Bowen, Bessette, and Cham (2006) have suggested that it is sufficient that the educational leaders, principals, assistant principals, superintendents, and associate superintendents should receive training in ethical principles and practices.

Thirdly, the research findings have revealed that as perceived by teachers, school leaders are acting immorally over their subordinates in an average. They are often committing immoral practices such as deceive his/her subordinates, abuse/attack staff members, insulting and harass subordinates, diminishing employees' dignity, and breaching the agreement. To avoid such unethical conduct from school leaders, Mihelič, Lipičnik, and Tekavčič (2010) have indicated that if the leader 'walks the talk' by translating internalized values into action, they will generate higher levels of trust and respect from their followers. It is recommended that school leaders are expected to be role models for their subordinates, and school administrators should offer them short term training.

In brief, school leaders should be better equipped and well-appointed to respond and encounter presentday school leadership challenges through professional development approaches that take into account the ethical complexity of school-based management. To further elaborate, school leaders have a key role in managing schools because they are the main decisionmakers. The school leaders, therefore, have more responsibilities than the other staff has. Henceforth it is clear that the school leaders' ethical behavior directly affects the schools' climate of positivity. Though, this research's findings cannot be generalized to all Ethiopian primary schools as it is conducted in only primary schools of the Eastern part of the country. It is recommended that detailed research can be conducted to include more data in this area for the future.

\section{REFERENCES}

Amsale, F., Bekele, M., \& Tafesse, M. (2016). The ethical behaviors of educational leaders in Ethiopian public universities: The case of the western cluster universities. European Scientific Journal, 12(13), 359-379. https://doi:10.19044/esj.2016. v12n13p359.

Arar, K., Haj, I., Abramovitz, R., \& Oplatka, I. (2016). Ethical leadership in education and its relation to ethical decision-making: The case of Arab school leaders in Israel. Journal of Educational Administration, 54(6), 647-660. https://doi.org/10.1108/JEA-112015-0101.

Bowen, C., Bessette, H., \& Cham, T. C. (2006). Including ethics in the study of educational leadership. Journal of College and Character, 7(7), 1-8. https://doi. org/10.2202/1940-1639.1241.

Brown, M. E., Treviño, L. K., \& Harrison, D. A. (2005). Ethical leadership: A social learning perspective for construct development and testing. Organizational Behavior and Human Decision Processes, 97(2), 117134. https://doi.org/10.1016/j.obhdp.2005.03.002.

Cohen, J. (1988). Statistical power analysis for the behavioral sciences ( $2^{\text {nd }}$ Ed). Hillsdale, NJ: Lawrence Erlbaum Associates.

Cohen, L., Manion, L., \& Morrison, K. (2007). Research methods in education $\left(6^{\text {th }} \mathrm{Ed}\right)$. London: Routledge Falmer.

Creswell, J. W. (2012). Education research: Planning, conducting, evaluating, quantitative and qualitative research. United states of America: Pearson Education, inc.

Downe, J., Cowell, R., \& Morgan, K. (2016). What determines ethical behavior in public organizations: Is it rules or leadership? Public Administration Review, 76(6), 898-909. https://doi.org/10.1111/ puar. 12562.

Florida Department of Education. (2008). Florida Educational Leadership Standard 10 Ethical Leadership: The William Cecil Golden school leadership development program. Retrieved on April 17 $7^{\text {th }}, 2019$ from www.floridaschoolleaders.org.

Hassan, S., Mahsud, R., Yukl, G., \& Prussia, G. E. (2013). Ethical and empowering leadership and leader effectiveness. Journal of Managerial Psychology, 28(2), 133-146. https://psycnet.apa.org/ doi/10.1108/02683941311300252.

Hassan, S., Wright, B. E., \& Yukl, G. (2014). Does ethical leadership matter in government? Effects on organizational commitment, absenteeism, and willingness to report ethical problems. Public Administration Review, 74(3), 333-343. https://doi. org/10.1111/puar.12216.

Kalshoven, K., Den Hartog, D. N., \& De Hoogh,A. H. (2011). Ethical leadership at work questionnaire (ELW): Development and validation of a multidimensional measure. The Leadership Quarterly, 22(1), 51-69. https://doi.org/10.1016/J.LEAQUA.2010.12.007.

Kocabaş, I., \& Karakouml, T. (2009). Ethics in school administration. African Journal of Business Management, 3(4), 126-130. https://doi.org/10.5897/ AJBM.9000266.

Langlois, L., Lapointe, C., Valois, P., \& de Leeuw, A. (2014). Development and validity of the ethical leadership questionnaire. Journal of Educational Administration, 53(3), 310-331. https://doi:10.1108/ JEA-10-2012-0110.

Mark, R. L. (2001). Introduction to behavioral sciences. $\left(3^{\text {rd }}\right.$ Ed). USA: Allyn\& Bacon, Pearson Education Company.

Mihelič, K. K., Lipičnik, B., \& Tekavčič, M. (2010). Ethical leadership. International Journal of Management \& Information Systems, 14(5), 31-42. https://doi. org/10.19030/ijmis.v14i5.11.

Mills, G. E., \& Gay, L. R. (2016). Educational research $\left(11^{\text {th }}\right.$ Ed). New Jersey: Pearson. 
MOE. (2015). Education sector development Program (ESDP-V). Addis Ababa: Program Action Plan, Federal Ministry of Education.

Northouse, P. G. (2013). Leadership: Theory and practice. California: SAGE Publications.

Perry, J. L. (2015). Revisiting the core of our good government ethos. Public Administration Review, 75(2), 186-187.

Svara, J. H. (2014). Who are the keepers of the code? Articulating and upholding ethical standards in the field of public administration. Public Administration Review, 74(5), 561-569. https://doi.org/10.1111/ puar. 12230 .
Vanderstoep, S. W., \& Johnson, D. D. (2008). Research methods for everyday life: Blending qualitative and quantitative approaches. New Jersey: John Wiley \& Sons.

Weinberg, H. (2014). Ethical leadership in public services: A solid foundation for good government. Public Administration Review, 74(3), 344-345. https://doi. org/10.1111/puar.12226.

Yamane, T. (1967). Elementary sampling theory. NewYork: Hamper.

Yukl, G., Mahsud, R., Hassan, S., \& Prussia, G. E. (2013). An improved measure of ethical leadership. Journal of Leadership \& Organizational Studies, 20(1), 3848. https://doi.org/10.1177\%2F1548051811429352. 